\title{
Synthesis of Some Azo Disperse-Reactive Dyes From 2- Aminothiazole Derivatives And Their Application Properties On Polyester/Cotton Blend
}

\author{
Franker Amen Imadegbor, Kasali Ademola Bello, Abdul Raheem Giwa \\ Department of Textile Science and Technology, Ahmadu Bello University, Zaria, Nigeria.
}

\begin{abstract}
A series of some new disperse-reactive dyes was synthesized by diazo-coupling reaction of 2-amino4-phenylthiazole derivatives with pyridone, the disperse dyes thus obtained were refluxed with phosphorus oxychloride to obtain the disperse-reactive dyes. The dyes were characterized by IR spectral studies and visible absorption was carried out in various solvents. The dyeing performance of these dyes where assessed on polyester, nylon and polyester/cotton blend fabrics. These dyes where found to give various shades of red with good depth, brightness and leveling properties on the fabrics. The dyed fabric showed fairly good to very good light fastness and very good to excellent fastness to washing, perspiration and rubbing. The dyebath exhaustion and fixation on the polyester fabric was found to be very good.
\end{abstract}

Key words: 2-amino-4-phenylthiazole; phosphorus oxychloride; disperse-reactive dyes; dyeing; exhaustion; fixation; fastness; polyester/cotton blend.

\section{Introduction}

Monoazo disperse dyes with thiazolediazo components have been intensively investigated to produce bright and strong colour shades ranging from red to greenish blue on synthetic fibre.Colour Index described various basic, direct, vat and disperse dyes wherein thiazole nucleus occurs [1].

Before 1950, almost all the disperse blue dyes used were prepared from the anthraquinone class and had the limitations of poor dischargeability and sensitivity to oxide of nitrogen. Derivative of 2 -aminothiazole has a long history of use as heterocyclic diazo components for disperse dyes [2].

In this regard, azo dyes based on heterocyclic amines have been developed, and the resultant dyes have higher tinctorial strength and give brighter dyeings than those derived from aniline-based diazo components. For instance, amino-substituted thiazole, isothiazole, thiophene, and pyrazole compounds afford very electronegative diazo components and, consequently, provide a pronounced bathochromic effect compared to the corresponding benzenoid compounds [3-5].

In this paper, disperse dyes where synthesized by diazotization of some aminothiazole derivatives and then coupled to pyridone. These disperse dyes obtained were refluxed using phosphorus oxychloride to infuse reactive groups into the disperse dyes thereby obtaining the disperse-reactive dyes suitable for application on polyester/cotton blend fabrics. Spectral characteristics of these dyes were carried out also dye exhaustion and fixation were calculated and the various fastness tests such as washing, light, perspiration and rubbing were also investigated to determine the dye subtsantivity for the fabric.

\section{General information}

\section{Materials And Methods}

All the chemicals used in the synthesis of the dyes and intermediates were of analytical grade and were used without purification. Melting points were determined by the open capillary method using the Gallenkamp melting apparatus. The visible absorption spectra were measured using Jenway $6405 \mathrm{UV} / \mathrm{Vis}$ spectrophotometer, IR was measured and recorded in $\mathrm{KBr}$ pellets using the FTIR-8400S Fourier Transform Infra-red Spectrometer, and GC-MS using the GCMS-QP2010 PLUS SHIMDAZU Japan.

\section{Synthesis of 2-amino-4-phenylthiazole}

Resublimed iodine $(7.6 \mathrm{~g}, 0.03 \mathrm{~mol})$ was added to the slurry of acetophenone $(3.5 \mathrm{ml}, 0.03 \mathrm{~mol})$ and thiourea $(4.56 \mathrm{~g}, 0.06 \mathrm{~mol})$ and the mixture was heated in an oil bath at $130-140^{\circ} \mathrm{C}$ overnight. After cooling, the reactions mixture was diluted with distilled water $(50 \mathrm{ml})$ and heated to dissolve most of the solid, again cooled to ambient temperature and treated with $25 \%$ aqueous ammonium hydroxide (to $\mathrm{pH}-9-10$ ).

This procedure was repeated for the para-substituted acetophenones namely: chloro, methyl, methoxyl and nitro. 


\section{Synthesis of pyridone}

A mixture of ethylcyanoacetate $(56.56 \mathrm{~g}, 0.5 \mathrm{~mol})$ and ammonium hydroxide $(70 \mathrm{ml}, 0.5 \mathrm{~mol})$ was stirred until a clear solution was obtained and ethylacetoacetate $(65.07 \mathrm{~g}, 0.5 \mathrm{~mol})$ was added. The mixture was refluxed for 9 hours at $110^{\circ} \mathrm{C}$. The solution was diluted with water $(400 \mathrm{ml})$ and acidified with hydrochloric acid to give a white solid. This was filtered and washed with water.

\section{Diazotization of 2-amino-4-phenylthiazole}

Nitrosylsulphuric acid was used for the diazotization. It was prepared by adding sodium nitrite $(0.83 \mathrm{~g}$, $0.01 \mathrm{~mol})$ to sulphuric acid $(98 \% 11.96 \mathrm{~g}, 0.12 \mathrm{~mol})$ at $30^{\circ} \mathrm{C}$, heating the stirred mixture to $60-65^{\circ} \mathrm{C}$ over $15 \mathrm{mins}$ and maintaining this temperature for $30 \mathrm{mins}$ to ensure complete dissolution of the sodium nitrite. The reaction mixture was cooled to $5^{\circ} \mathrm{C}$, acetic acid $(5 \mathrm{ml})$ was added and stiring continued for $10 \mathrm{~min}$. The temperature was then reduced to $-5^{\circ} \mathrm{C}$, the appropriate aminothiazole $(0.01 \mathrm{~mol})$ was added over $30 \mathrm{~min}$ and the whole reaction mixture was stirred at the same low temperature for at least $2 \mathrm{hrs}$.

\section{Coupling diazotized 2-amino-4-phenylthiazole with Pyridone}

A solution of the coupling component $(0.13 \mathrm{~mol})$ in acetic acid $(15 \mathrm{ml})$ was added to an ice-water mixture $(200 \mathrm{~g})$ in a beaker equipped with a mechanical stirrer and $\mathrm{pH}$ meter. A pinch of sulphamic acid was added followed by the addition of the diazonium salt liquor $(0.13 \mathrm{~mol})$ at $0-5^{\circ} \mathrm{C}$ over $1 \mathrm{hr}$, the mixture was stirred for at least $3 \mathrm{hrs}$ at ambient temperature. During the addition and stirring period the $\mathrm{pH}$ was adjusted to $1.5-2.0$ by drop-wise addition of aqueous sodium hydroxide to the coupling bath. Finally the $\mathrm{pH}$ was raised to 4.0-4.5 and the precipitated product was collected, washed with cold and hot water and dried. The product was recrystallized from methylated spirit.

The physical properties of the various dyes are shown in Table 1.

\section{Synthesis of disperse-reactive dyes}

The disperse dyes $(2.5 \mathrm{~g}, 0.01 \mathrm{~mol})$ were refluxed with phosphorus oxychloride $(40 \mathrm{ml}$, S.G 1.675 , $0.432 \mathrm{~mol})$. On addition of the phosphorus oxychloride, the colour changed from red to yellow and then red after $1 \mathrm{hr}$ reflux. Refluxing was continued until the reaction was complete (10hrs). Most of the phosphorus oxychloride were then distilled under vacuum and the remaining mixture (about 10ml) was added to ice-water (about $300 \mathrm{~g}$ ) with vigorous stirring. The resulting dark oily compound yielded on prolonged stirring a red solid. The product was filtered and washed acid free with water and dried at $40-50^{\circ} \mathrm{C}$. It was recrystallized from benzene to yield red crystals.

The physical properties of the synthesized dyes are shown in Table 1.

IR spectra and visible absorption spectra are recorded in tables 2 and 3.

\section{Dyeing of Polyester}

The dye baths were prepared from the dye $\left(2 \%\right.$ O.W.F) with a dispersol-levelling agent $\left(1 \mathrm{~g} \cdot{ }^{1}\right.$ litre $)$ and $5 \%$ toluene as carrier to a final liquor of $50: 1$, w/w. The $\mathrm{pH}$ value of the bath was adjusted to $4-5$ with acetic acid $(10 \%)$. The polyester fabrics, previously wetted, were placed into the liquor at $25^{\circ} \mathrm{C}-30^{\circ} \mathrm{C}$. The temperature was raised to $100^{\circ} \mathrm{C}$ at the rate of $2^{\circ} \mathrm{C} / \mathrm{min}$, and dyeing continued for $60 \mathrm{~min}$. After cooling, the dyed fabrics were reduction cleared in sodium hydroxide $\left(2 \mathrm{~g} \cdot{ }^{1}\right.$ litre $)$, dispersing agent $\left(1.5 \mathrm{~g} \cdot{ }^{1}\right.$ litre $)$ and sodium dithionite $\left(2 \mathrm{~g} \cdot{ }^{1}\right.$ litre $)$ at $60^{\circ} \mathrm{C}$ for $30 \mathrm{mins}$ and then washed and dried. Percentage exhaustion was calculated to determine the dye absorption unto the fabric.

\section{Dyeing of Nylon}

The procedure carried out for dyeing of the polyester fabric was repeated here but this time without a carrier.

\section{Dyeing of Polyester/cotton blend}

The procedure described above for dyeing of polyester was carried out and at the end of the dyeing process, the temperature was reduced to $70^{\circ} \mathrm{C}$ and the dye bath made alkaline (with $0.1 \mathrm{M}$ sodium hydroxide) to fix the reactive dye unto the cotton. This was done for 30mins after which the fabric was removed, squeezed, thoroughly rinsed under a running tap and allowed to dry at room temperature.

The polyester/cotton blend was also dyed with the disperse-reactive dyes but this time without the alkaline fixation. This was done in order to compare the fixation values with that in which alkaline fixation were carried out. 
Fastness Tests

The various fastness tests such as washing, light, perspiration and rubbing was carried out. The wash fastness test was carried out using the ISO number 3 method, the light and perspiration fastness was assessed in accordance with BS:10061978 while the rubbing fastness test was carried out usingcrockmeter (Atlas) in accordance with AATCC-1961.

The \%exhaustion and \%fixation was carried out according to known method [6].

The results for the exhaustion and fixation values and also the fastness tests are shown in tables 4-7.

\section{Synthesis of Dyes and Intermediates}

\section{Results And Discussion}

2-amino-4-phenylthiazoles (1a-1e) were prepared from acetophenone and thiourea in the presence of resublimed iodine.

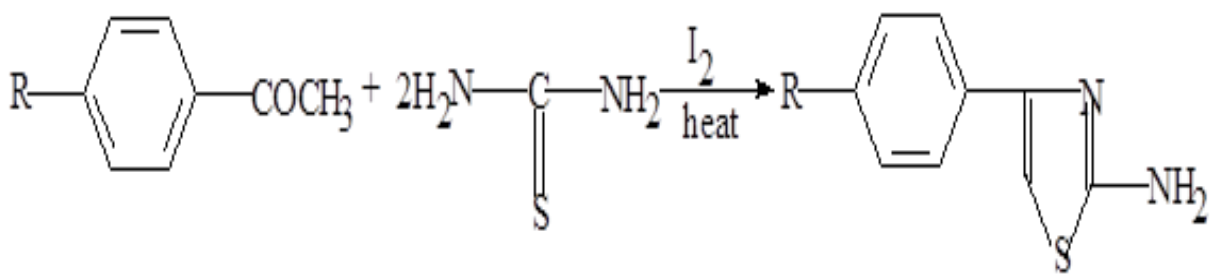

Scheme 1: Schematic route for the synthesis of 2-amino-4-phenylthiazole

$\mathrm{R}=1$ (a) $\mathrm{H}, 1$ (b) $\mathrm{Cl}, 1$ (c) $\mathrm{CH}_{3}, 1$ (d) $\mathrm{OCH}_{3}, 1$ (e) $\mathrm{NO}_{2}$.

\section{Synthesis of Pyridone.}

The coupling component pyridone (2a) was synthesized from ethylcyanoacetate, ethylacetoacetate and ammonium hydroxide.<smiles>COC(=O)COC(=O)CC(C)=O</smiles>

Scheme 2: Schematic route for the synthesis of pyridone

The 2-amino-4-phenylthiazoles were then diazotized using the nitrosylsulphuric acid method and the diazonium salts (3a-3e) were coupled topyridone (2a).

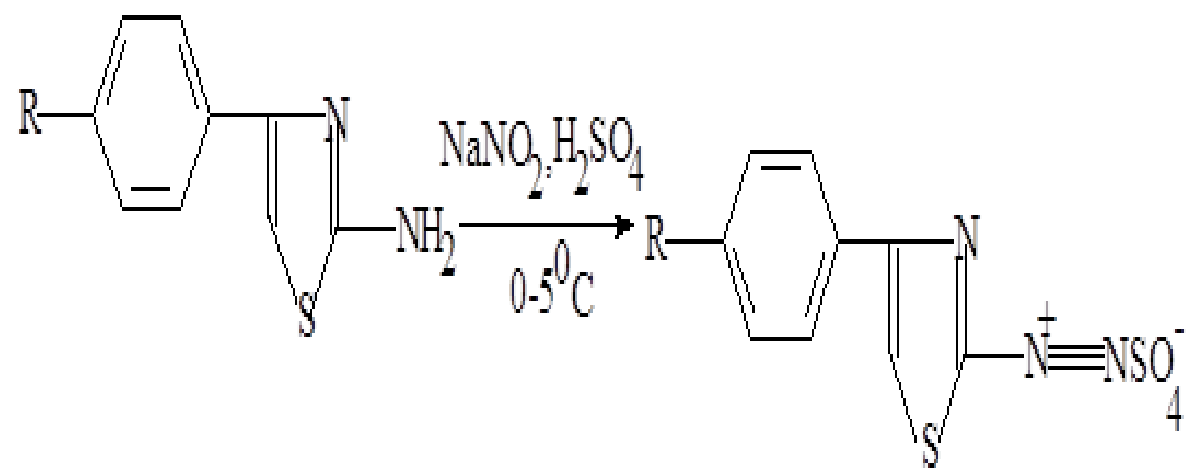

Scheme 3: Schematic route for the diazotization of 2-amino-4-phenylthiazole. 


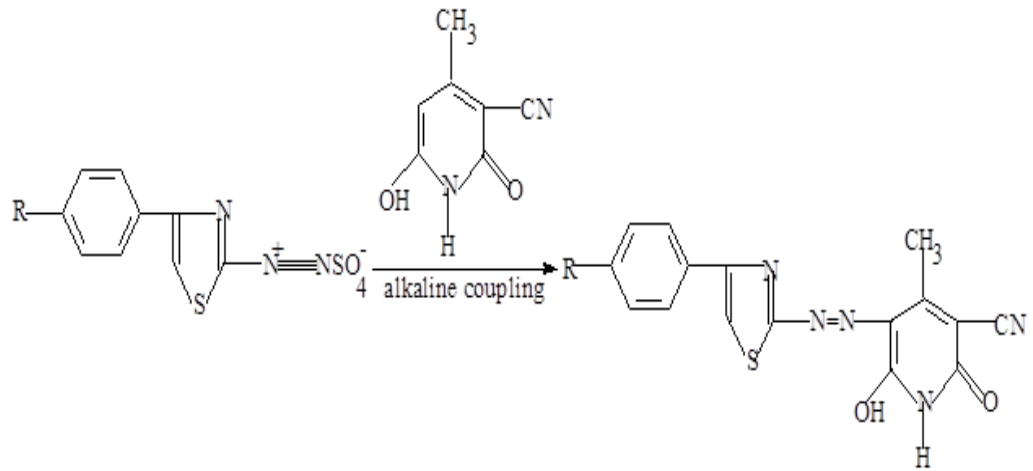

Scheme 4: Schematic route for the synthesis of disperse dyes 4a-4e.

The azo disperse dye (4a-4e) thus obtained were purified by recrystallization from methylated spirit. The disperse-reactive dyes (5a-5e) were obtained by refluxing these disperse dyes with phosphorus oxychloride for about $10 \mathrm{hrs}$. These dyes were then purified by recrystallization from benzene to obtain red crystals.

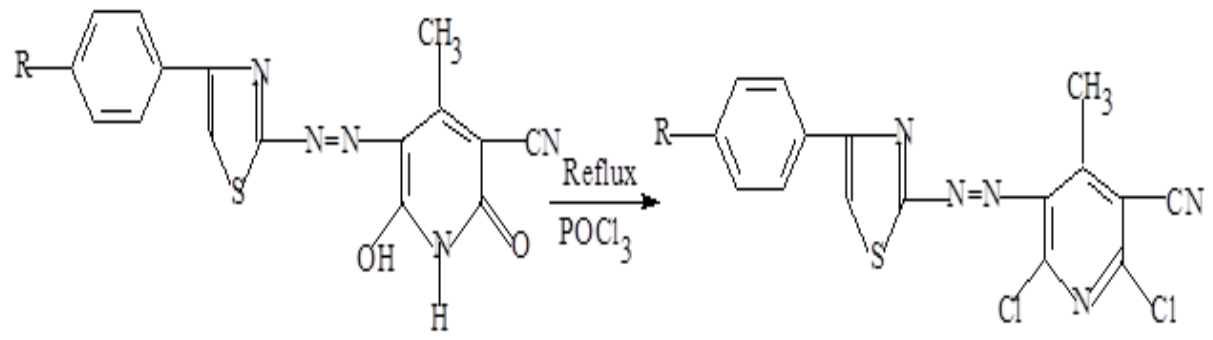

Scheme 5: Schematic route for the synthesis of disperse-reactive dyes 5a-5e

The structures of the intermediates were confirmed using IR while the structure of the dyes was confirmed using IR and GC-MS. The physical characteristics of the dyes are shown in table 1.

\begin{tabular}{lllll}
\multicolumn{4}{c}{ Table 1 Physical Properties of Synthesized Dyes } \\
\hline Dye No & Molecular weight & Melting point & \% Yield & Colour \\
\hline 4a & 337 & 145 & 74 & Red \\
4b & 372 & 143 & 91 & Deep red \\
4c & 352 & 160 & 83 & Red \\
4d & 368 & 164 & 50 & Light red \\
4e & 383 & 158 & 47 & Light red \\
$5 \mathrm{a}$ & 374 & 176 & 72 & Red \\
$5 \mathrm{~b}$ & 409 & 156 & 92 & Deep red \\
5c & 389 & 214 & 86 & Deep red \\
$5 \mathrm{~d}$ & 405 & 220 & 46 & Light red \\
$5 \mathrm{e}$ & 416 & 184 & 40 & Light red \\
\hline
\end{tabular}

Infrared Spectra of the Intermediates and Dyes

Table 2 IR Spectra of Synthesized Dyes

\begin{tabular}{|c|c|c|c|c|c|c|c|c|c|c|}
\hline $\begin{array}{l}\text { DYE } \\
\text { NO }\end{array}$ & $\begin{array}{l}\text { Ar.C- } \\
\mathrm{H}\end{array}$ & $\mathrm{C}-\mathrm{H}$ & $\mathrm{N}-\mathrm{H}$ & $\mathrm{C}=\mathrm{C}$ & $\mathrm{N}=\mathrm{N}$ & $\mathrm{C}-\mathrm{N}$ & $\mathrm{N}=\mathrm{C}=\mathrm{S}$ & $\mathrm{C}=\mathrm{O}$ & $\mathrm{O}-\mathrm{H}$ & $\mathrm{C}-\mathrm{Cl}$ \\
\hline & Bend & Stretch & bend/Stretch & Stretch & & Stretch & & stretch & Stretch & \\
\hline $1 \mathrm{a}$ & 700.18 & $\begin{array}{l}1036.77 \\
1188.19\end{array}$ & $\begin{array}{l}3421.83(\mathrm{~s}) \\
1610.61(\mathrm{~b})\end{array}$ & 1513.21 & - & - & 1980.00 & & - & - \\
\hline $1 b$ & $\begin{array}{l}725.26 \\
823.21\end{array}$ & $\begin{array}{l}1080.17 \\
1195.91\end{array}$ & $\begin{array}{l}3391.94(\mathrm{~s}) \\
1612.54(\mathrm{~b})\end{array}$ & 1505.49 & - & - & 1952.99 & & - & \\
\hline $1 \mathrm{c}$ & $\begin{array}{l}725.26 \\
825.56\end{array}$ & $\begin{array}{l}1043.52 \\
1187.23\end{array}$ & $\begin{array}{l}3392.90(\mathrm{~s}) \\
1616.40(\mathrm{~b})\end{array}$ & - & - & - & 2193.14 & - & - & - \\
\hline $1 d$ & 793.73 & 1003.98 & $3336.00(\mathrm{~s})$ & - & - & & - & - & - & - \\
\hline $2 \mathrm{a}$ & - & $\begin{array}{l}995.30 \\
1086.92\end{array}$ & $\begin{array}{l}3274.27(\mathrm{~s}) \\
1600.97(\mathrm{~b})\end{array}$ & - & - & $\begin{array}{l}1203.62 \\
2187.35 \\
\text { (nitriles) }\end{array}$ & & 1829.54 & $\begin{array}{l}3784.46 \\
3392.90\end{array}$ & - \\
\hline $4 a$ & 869.92 & 1049.31 & 3200.98 (s) & 1509.35 & 1412.90 & 1203.62 & 2225.93 & 1670.41 & 3436.30 & - \\
\hline $4 b$ & 862.21 & $\begin{array}{l}1045.45 \\
1181.41\end{array}$ & $3181.69(\mathrm{~s})$ & 1528.64 & 1407.12 & 1291.39 & 2230.48 & 1677.16 & 3361.07 & - \\
\hline $4 c$ & 860.28 & 1154.43 & - & 1528.64 & 1438.94 & - & 2223.03 & 1627.97 & 3414.12 & - \\
\hline $4 d$ & 812.06 & & $3145.04(\mathrm{~s})$ & - & 1384.94 & 1199.76 & 2212.43 & 1622.19 & 3315.74 & \\
\hline
\end{tabular}


Synthesis of Some Azo Disperse-Reactive Dyes from 2-Aminothiazole Derivatives And Their.

\begin{tabular}{|c|c|c|c|c|c|c|c|c|c|c|}
\hline $4 \mathrm{e}$ & 860.28 & 1055.10 & $3145.04(\mathrm{~s})$ & 1521.89 & 1353.11 & 1202.66 & 2222.93 & 1645.33 & 3323.46 & \\
\hline $5 \mathrm{a}$ & $\begin{array}{l}738.76 \\
887.26\end{array}$ & 1008.80 & $\begin{array}{l}3119.96(\mathrm{~s}) \\
1680.05(\mathrm{~b})\end{array}$ & 1517.06 & 1363.28 & 1174.69 & 2240.39 & - & 3389.04 & 2359.98 \\
\hline $5 b$ & 851.60 & 1011.70 & 1678.13 (b) & 1517.06 & 1352.83 & 1195.91 & 2240.39 & - & 3394.83 & 2374.45 \\
\hline $5 c$ & 810.13 & 1011.70 & $\begin{array}{l}3131.54(\mathrm{~s}) \\
1627.97(\mathrm{~b})\end{array}$ & 1511.28 & 1378.23 & 1197.83 & 2229.79 & - & 3390.96 & 2369.69 \\
\hline $5 d$ & 801.45 & $\begin{array}{l}996.27 \\
1004.95\end{array}$ & $\begin{array}{l}3139.25(\mathrm{~s}) \\
1632.80(\mathrm{~b})\end{array}$ & - & 1354.07 & - & - & - & 3353.03 & 2368.66 \\
\hline $5 e$ & 791.81 & 1004.92 & $\begin{array}{l}3148.90(\mathrm{~s}) \\
1649.19(\mathrm{~b})\end{array}$ & - & 1348.29 & - & 2220.45 & - & 3275.24 & 2381.20 \\
\hline
\end{tabular}

As can be seen from table 2, aromatic C-H stretching vibration occurs at $700.18 \mathrm{~cm}^{-1}-887.26 \mathrm{~cm}^{-1}$, C-H stretching vibration occurs at $995.30 \mathrm{~cm}^{-1}-1188.19 \mathrm{~cm}^{-1}, \quad \mathrm{~N}=\mathrm{N}$ stretching vibration which corresponds to the azochromophore occurs for $4 \mathrm{a}-5 \mathrm{e}$ at $1348.29 \mathrm{~cm}^{-1}-1428.94 \mathrm{~cm}^{-1}, \mathrm{C}-\mathrm{N}$ stretch for amines occurred for almost all the dyes at $1174.69 \mathrm{~cm}^{-1}-1203.62 \mathrm{~cm}^{-1}$ also at $2187.35 \mathrm{~cm}^{-1}$ which corresponds to $\mathrm{C}=\mathrm{N}$ (nitrile) for $2 \mathrm{a}$ (pyridone), $\mathrm{C}=\mathrm{C}$ stretching vibration occurs at $1505.49 \mathrm{~cm}^{-1}-1528.64 \mathrm{~cm}^{-1}, \mathrm{C}=\mathrm{O}$ stretching vibration occurs for dyes $4 \mathrm{a}-4 \mathrm{e}$ at $1622.19 \mathrm{~cm}^{-1}-1670 \mathrm{~cm}^{-1}$ and at $1829.54 \mathrm{~cm}^{-1}$ for $2 \mathrm{a}, \mathrm{N}-\mathrm{H}$ stretching and bending vibrations can be seen for almost all the dyes and intermediates. N-H bending vibration occurs at $1600.97 \mathrm{~cm}^{-1}-1680.05 \mathrm{~cm}^{-1}$ and $\mathrm{N}-\mathrm{H}$ stretching vibration occurs at $3145.04 \mathrm{~cm}^{-1}-3421.83 \mathrm{~cm}^{-1}, \mathrm{~N}=\mathrm{C}=\mathrm{S}$ (isothiocyanate) stretching occurs for almost all the intermediates and dyes at $1952 \mathrm{~cm}^{-1}-2240.39 \mathrm{~cm}^{-1} \mathrm{C}-\mathrm{Cl}$ vibration can be seen for dyes $5 \mathrm{a}-5 \mathrm{e}$ which are the disperse-reactive dyes at $2359.98 \mathrm{~cm}^{-1}-2381.20 \mathrm{~cm}^{-1}$ and $\mathrm{O}-\mathrm{H}$ stretching vibration occurs for dyes $4 \mathrm{a}-4 \mathrm{e}$ at $3275.24 \mathrm{~cm}^{-1}-3436.40 \mathrm{~cm}^{-1}$ and at $3784.46 \mathrm{~cm}^{-1}$ for $2 \mathrm{a}$.

\section{Visible Absorption Spectra of Dyes}

Table 3 Visible Absorption Spectra of Synthesized Dyes

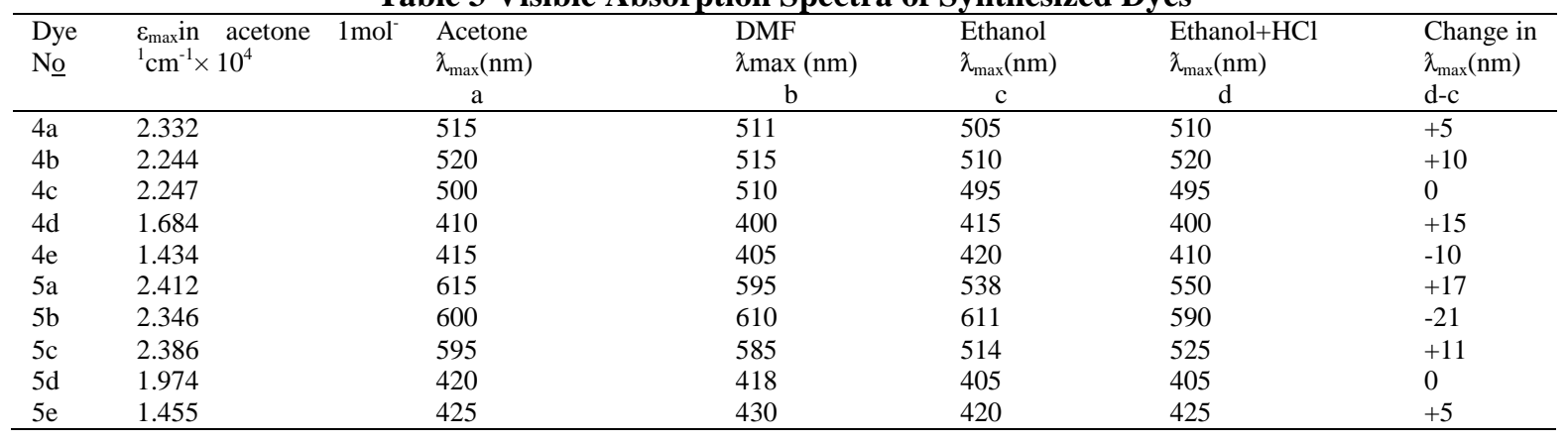

The visible absorption spectra of the synthesized dyes was taken in acetone, dimethyl formamide (DMF), ethanol and in ethanol plus a drop of $\mathrm{HCl}$, this was to compare the various solvent polarity for the synthesized dyes. From the results summarized in table 3 it can be seen that the dyes showed higher absorption wavelength in acetone. The molar extinction coefficient was also calculated from a standard solution using acetone as the solvent.

The effects of solvent polarity on the maximum absorption wavelength of the dyes were also studied. The results shows that most of the dyes showed positive solvatochromism when the solvent is changed to a more polar solvents. For example dye (4a) absorbs at $505 \mathrm{~nm}$ in ethanol but when the solvent is changed to a more polar solvent, acetone it absorbs at $515 \mathrm{~nm}$ indicating a bathochromic shift of $10 \mathrm{~nm}$. Also dye (4b) exhibits this same effect as it absorbs at $510 \mathrm{~nm}$ in ethanol and $520 \mathrm{~nm}$ in acetone. Dyes (5a) and (5c) show the greatest effects of positive solvatochromism as it absorbs at $538 \mathrm{~nm}$ in ethanol and 615 in acetone also dye $5 \mathrm{c}$ absorbs at $514 \mathrm{~nm}$ in ethanol and $595 \mathrm{~nm}$ in acetone indicating a bathochromic shift of +77 and $+81 \mathrm{~nm}$ respectively.

Some of the dyes however, showed negative sovatochromism when solvent is changed to a more polar solvents. For example dyes (4d) and (4e) absorbs at $415 \mathrm{~nm}$ and $420 \mathrm{~nm}$ in ethanol and when the solvent was changed to acetone it absorbs at $410 \mathrm{~nm}$ and $415 \mathrm{~nm}$ indicating a negative solvatochromism (hypsochromic shift) of $-5 \mathrm{~nm}$. Dye $(5 \mathrm{~b})$ show the greatest effect of negative solvatochromism as it absorbs at $611 \mathrm{~nm}$ in ethanol and $600 \mathrm{~nm}$ in acetone indicating negative solvatochromism of $-11 \mathrm{~nm}$.

Also from table 3 most of the dyes showed positive halochromism. For example dye (4a) absorbs at $505 \mathrm{~nm}$ in ethanol and when a drop of $\mathrm{HCl}$ is added to its ethanolic solution it absorbs at 510nm indicating a positive halochromism of $5 \mathrm{~nm}$. Similarly, dyes (4b), (4d), (5c) and (5e) showed similar effect of positive halochromism with values of $+10 \mathrm{~nm},+5 \mathrm{~nm},+11 \mathrm{~nm}$ and $+5 \mathrm{~nm}$. Dye $(5 \mathrm{a})$ showed the greatest effect of positive halochromism of $+17 \mathrm{~nm}$. A few of these dyes showed negative halochromism for example dye (4e) absorbs at $420 \mathrm{~nm}$ in ethanol and when a drop of $\mathrm{HCl}$ is added to the solution, it absorbs at $410 \mathrm{~nm}$ indicating a negative halochromism of $-10 \mathrm{~nm}$ similar effect occur with dye $(5 \mathrm{~b})$ giving a negative halochromism of $-21 \mathrm{~nm}$. 


\section{Dyeing and Fastness properties}

The dyes were applied to polyester, nylon and polyester/cotton blend using the methods described above.The dyes gave very good levelness and fibre penetration on polyester nylon and polyester/cotton blend. The exhaustion was good up to $95 \%$ and fixation values up to $93 \%$. The dyes gave very-good to moderate wash, perspiration and rubbing fastness while the light fastness result was between good to fair. The results show that nylon gave higher exhaustion values than polyester for most of the dyes this can be attributed to the amorphous nature of the nylon fabric and hence easy penetration of the dye molecules than the polyester fabric which is highly crystalline. It can also be seen from table 5 that the \%fixation was higher for those in which alkaline fixation were carried out indicating that alkaline fixation is necessary when dyeing polyester cotton blend with disperse-reactive dyes to fix the reactive dyes on the cotton component of the blend.

Table $4 \%$ Exhaustion and Fixation of Synthesized Dyes

\begin{tabular}{|c|c|c|c|c|c|c|}
\hline Dye No & \%exhaustion & \%exhaustion & \%exhaustion & \%fixation & \%exhaustion & \%fixation \\
\hline & Polyester & Nylon & \multicolumn{2}{|c|}{ Polyester-cotton blend } & \multicolumn{2}{|c|}{ Polyester-cotton blend } \\
\hline & & & \multicolumn{2}{|c|}{ With alkali fixation } & \multicolumn{2}{|c|}{ Without alkali fixation } \\
\hline $4 \mathrm{a}$ & 90 & 92 & - & - & - & - \\
\hline $4 b$ & 94 & 95 & - & - & - & - \\
\hline $4 c$ & 93 & 95 & - & - & - & - \\
\hline $4 d$ & 52 & 46 & - & - & - & - \\
\hline $4 \mathrm{e}$ & 54 & 49 & - & - & - & - \\
\hline $5 \mathrm{a}$ & - & - & 93 & 90 & 72 & 45 \\
\hline $5 b$ & - & - & 95 & 93 & 75 & 43 \\
\hline $5 c$ & - & - & 94 & 85 & 70 & 41 \\
\hline $5 d$ & - & - & 46 & 41 & 38 & 12 \\
\hline $5 e$ & - & - & 53 & 50 & 40 & 16 \\
\hline
\end{tabular}

Table 5 Washing and Light Fastness Results

\begin{tabular}{|c|c|c|c|c|c|c|}
\hline \multirow[t]{2}{*}{ Dye no } & \multicolumn{2}{|c|}{ Polyester } & \multicolumn{2}{|l|}{ Nylon } & \multicolumn{2}{|c|}{ Polyester-cotton } \\
\hline & Wash & Light & Wash & Light & Wash & Light \\
\hline $4 a$ & $4-5$ & 3 & $3-4$ & 4 & - & - \\
\hline $4 b$ & $3-4$ & 4 & $4-5$ & 4 & - & - \\
\hline $4 c$ & 3 & 2 & 4 & 3 & - & - \\
\hline $4 d$ & 4 & 5 & 3 & 3 & - & - \\
\hline $4 \mathrm{e}$ & $3-4$ & 5 & 3 & - & - & - \\
\hline $5 \mathrm{a}$ & - & - & - & - & 5 & 3 \\
\hline $5 b$ & - & - & - & - & $4-5$ & 6 \\
\hline $5 c$ & - & - & - & - & $3-4$ & 4 \\
\hline $5 d$ & - & - & - & - & $4-5$ & 5 \\
\hline $5 e$ & - & - & - & - & 4 & 4 \\
\hline
\end{tabular}

Table 6 Perspiration Fastness results

\begin{tabular}{|c|c|c|c|c|c|c|}
\hline Dye no & Polyester & & Nylon & & Polye & \\
\hline & Acid & Alkaline & Acid & Alkaline & Acid & Alkaline \\
\hline $4 a$ & 4 & $4-5$ & $4-5$ & $4-5$ & - & - \\
\hline $4 b$ & 3 & 4 & $3-4$ & $4-5$ & - & - \\
\hline $4 c$ & 2 & 2 & $2-3$ & 2 & - & - \\
\hline $4 d$ & $3-4$ & $3-4$ & 4 & $3-4$ & - & - \\
\hline $4 \mathrm{e}$ & $2-3$ & 3 & 2 & $2-3$ & - & - \\
\hline $5 a$ & - & - & - & - & $4-5$ & 5 \\
\hline $5 b$ & - & - & - & - & 4 & $4-5$ \\
\hline $5 c$ & - & - & - & - & 3 & $2-3$ \\
\hline $5 d$ & - & - & - & - & $3-4$ & 4 \\
\hline $5 e$ & - & - & - & - & $2-3$ & $2-3$ \\
\hline
\end{tabular}

Table 7 Rubbing Fastness Results

\begin{tabular}{lllllll}
\hline Dye no & Polyester & \multicolumn{3}{c}{ Nylon } & Polyester-cotton \\
\hline & Dry & Wet & Dry & Dry & Wet \\
\hline 4a & 5 & 4 & $4-5$ & 4 & - & - \\
$4 \mathrm{~b}$ & $3-4$ & 3 & $4-5$ & 3 & - & - \\
$4 \mathrm{c}$ & $2-3$ & 2 & 3 & $5-3$ & - & - \\
$4 \mathrm{~d}$ & $4-5$ & 4 & 4 & $3-4$ & - & - \\
$4 \mathrm{e}$ & $3-4$ & 4 & - & - & - & $4-5$ \\
$5 \mathrm{a}$ & - & - & - & - & 4 & $3-4$ \\
$5 \mathrm{~b}$ & - & - & - & - & $3-4$ & 3 \\
$5 \mathrm{c}$ & - & - & - & - & $4-5$ & $3-4$ \\
$5 \mathrm{~d}$ & - & - & - & 4 & $4-5$ \\
$5 \mathrm{e}$ & - & & - & - & \\
\hline
\end{tabular}




\section{Conclusion}

A series of aminothiazole and substituted aminothiazole disperse dyes which were further converted with phosphorus oxychlorideto disperse-reactive dyes was achieved in this work. This synthesis was obtained using conventional methods and the synthesis is extremely convenient and relatively inexpensive. Thesedyes provide bright shades of red and an outstanding property of these dyes is their high affinity and intensity of colour with only a small molecule of the dyes. The nature of the substituents in the diazo component has little or no effect in the visible absorption spectra and shade of the dyeing. Furthermore these dyes show good exhaustion, fixation, and uniform dyeing properties in addition to the good fastness properties. These dyes can hence be used commercially.

\section{References}

[1]. O. Annen, R. Egli, R. Hansler, B. Henzi, H. Jakob, P. MatzingerRev. Prog.Colour. 17 (1987), pp. 72-85.

[2]. L. Shuttleworth, M.A. Weaver D.R. Waring, G. Hallas (Eds.), The Chemistry and Application of Dyes, Plenum Press, New York (1990), pp. 107-162.

[3]. CV Stead RevProg Color.(1970)1:23.G. HallasJournal of the Society of Dyers and Colourists(1997) 95: 285.

[4]. J. GriffthsRev Prog Color.(1981) 11:37.

[5]. H. R. Maradiya and V. S. Pattel, "Thiophene Based Mono- azo Disperse Dyes for Polyester Fabric," Journal of the Serbian Society, Vol. 67, No. 1, 2002, pp. 17-25. doi:10.2298/JSC0201017M .

[6]. K. J. Sakoma, K. A. Bello and M. K. Yakubu, "Synthesis of Some Azo Disperse Dyes from 1-Substituted 2-Hydroxy-6-pyridone Derivatives and Their Colour Assessment on Polyester Fabric,” open Journal of Applied Sciences, Vol. 2, 2012, pp. 54-59, doi:10.4236/ojapps.2012.21006. 